\title{
FORECASTING AND ASSESSMENT OF LAND CONDITIONS USING NEURAL NETWORKS
}

\author{
A. Khokhriakova ${ }^{a}$, V. Grishkin \\ Saint Petersburg State University, 7-9 Universitetskaya emb., Saint Petersburg, 199034, \\ Russia \\ E-mail: ${ }^{a}$ st056061@student.spbu.ru
}

In some regions, mainly occupied by agriculture and cattle breeding, irreversible soil changes, e.g. desertification, have appeared, which can lead to serious environmental and economic problems. This paper considers the application of neural networks for prediction and assessment of desertificationprone lands using satellite images. An autoencoder type of the neural network is applied for these purposes. Datasets were generated for training from the Sentinel-2 satellite open database. The first network was used for prediction. The second network is responsible for segmentation of the image into classes using NDVI index. In this paper we explain the method, the architecture of the network and present some experimental results. The presented method allows making a qualitative and quantitative assessment of possible changes, which can be useful for planning preventive works.

Keywords: desertification, forecasting, satellite images, multispectral images, neural network, autoencoder

Anastasiia Khokhriakova, Valery Grishkin

Copyright (C) 2021 for this paper by its authors. Use permitted under Creative Commons License Attribution 4.0 International (CC BY 4.0). 


\section{Introduction}

Desertification is one of the problems which can have a negative impact on the economy and agriculture. Almost 30\% of the land area are deserts and semi-deserts and about 5\% of it are located on the territory of Russia, predominantly in the south near the Caspian Sea. And each year situation become worse [1-2].

It would be useful to predict what could happen in a few years and to evaluate qualitative and quantitative changes to plan campaigns to prevent negative changes. Satellite images can be used for this purpose. The process is divided into 2 steps: prediction and segmentation. An autoencoder type neural network was chosen for both of them.

\section{Datasets}

There are no suitable datasets for the considered purpose, so special sets of images were created. Google Earth Engine [3] allows users to download satellite images in a high quality for free. Sentinel-2 level 2a was chosen because it has extra tools for preprocessing, and it is possible to download images in different spectrum.

The area of The Republic of Kalmykia, which is approximately 85000 square kilometers, was chosen. It was divided into 72 parts. The images were downloaded in RGB. The side of one pixel corresponds to 10 meters. Data was downloaded for the period 1st April - 1st October of 2019 and 2020 years. Each image was divided into squares 64x64. Finally, dataset contains almost 400000 pairs.

\section{Prediction}

Prediction is the first stage. Since the images were downloaded for 2019 and 2020 years, the network will predict a year ahead. The following are examples of this dataset [fig. 1]. Left image is an input and right image is an output.

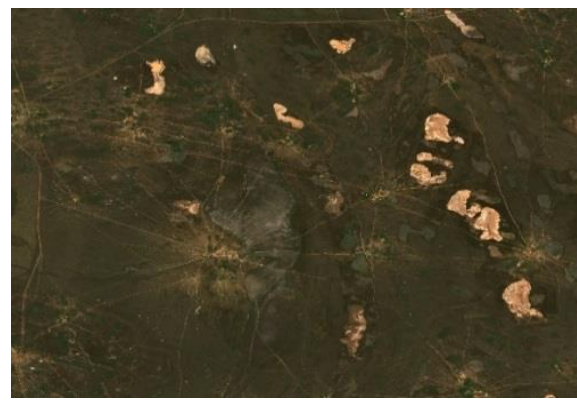

(a)

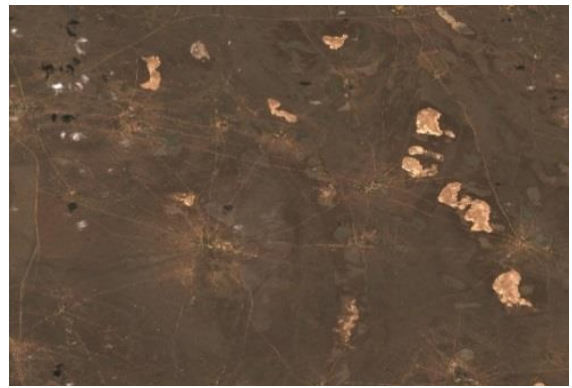

(b)

Figure 1. Dataset's elements: a) 2019 year (input) b) 2020 year (output)

An autoencoder type of neural networks was selected for the considering purpose. An important advantage of autoencoders is also the fact that autoencoders are auto-associative networks. Therefore, their customization is carried out through self-learning (unsupervised learning) and does not require the involvement of large and representative databases of labeled data. It consists of two parts [4]. The first part is encoder. The architecture of encoder is presented in figure 2. 


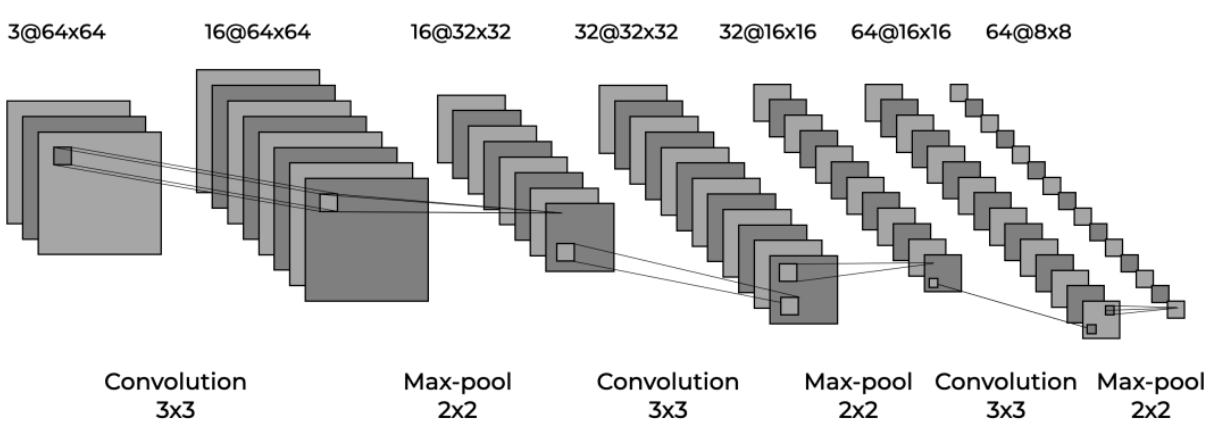

Figure 2. The architecture of encoder

The architecture of decoder is presented in the figure 3.

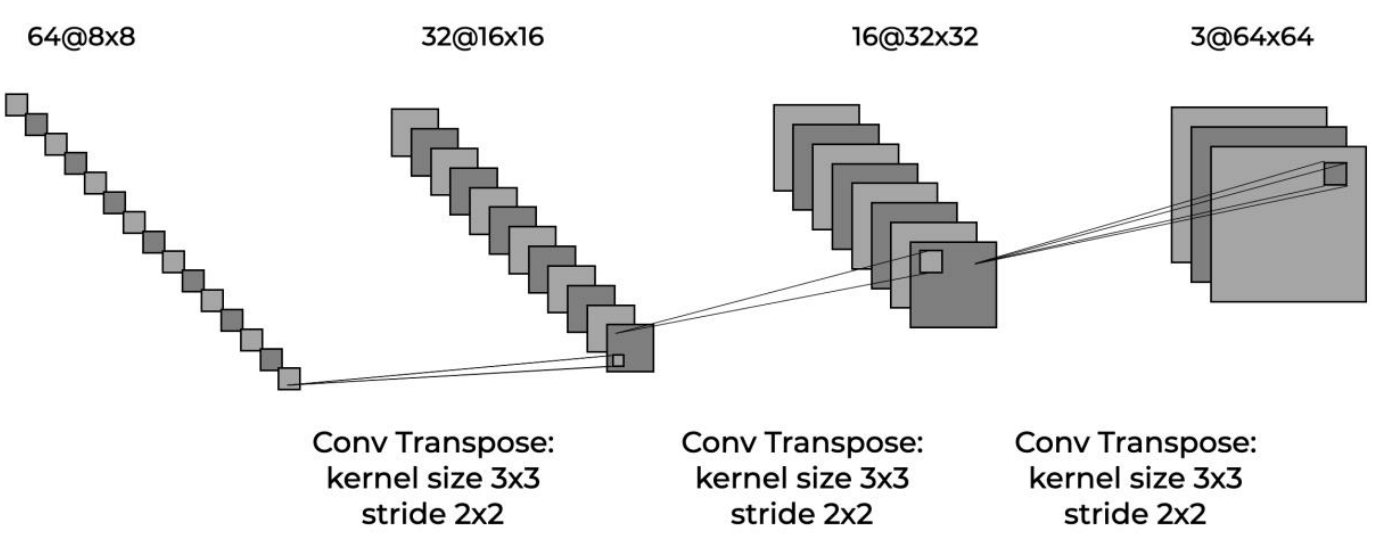

Figure 3. The architecture of decoder

\section{Segmentation}

The second stage is segmentation and assessment of changes. Initially SCL band (Scene Classification Map) which contains 11 classes (water, bare soils, vegetation, clouds etc.) was considered as a source of training data, but the quality of these images wasn't suitable. But this satellite has other useful bands. It has NIR and RED images to form NDVI images [5].

$$
N D V I=\frac{N I R-R E D}{N I R+R E D}
$$

NDVI is an index, which can be used to distinguish different types of objects depending on its value [table 1].

Table 1. Object type depending on NDVI value

\begin{tabular}{|c|c|}
\hline Object Type & NDVI value \\
\hline Dense vegetation & 0.7 \\
\hline Sparse vegetation & 0.5 \\
\hline Open soil & 0.025 \\
\hline Clouds & 0 \\
\hline Snow and ice & -0.05 \\
\hline Water & -0.25 \\
\hline Artificial materials (concrete, asphalt) & -0.5 \\
\hline
\end{tabular}


NDVI images are suitable for determining bare soils and vegetation. Dataset of these images can be used for teaching the second network. Applying digital image processing techniques to the resulting image it is possible to find desert areas and evaluate changes.

\section{Experimental results}

Training parameters for the network were:

- Images: 200000 pairs of RGB images 64x64

- $\quad$ Loss functions: The mean squared error (MSE) and the binary cross-entropy (BCE)

- $\quad$ Optimizer: Adam

- $\quad$ Metrics: Accuracy

- $\quad$ Number of epochs: 70

Graphs of loss-functions and of accuracy for training and validation parts were received [fig. 4-5]. MSE function gives values of loss-functions an order of magnitude less.

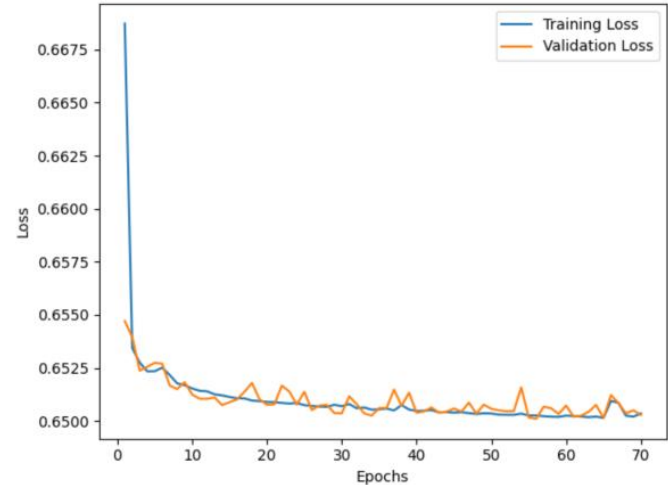

(a)

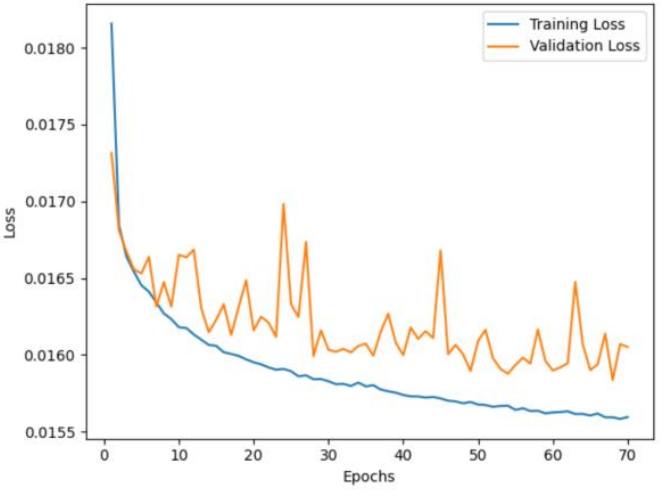

(b)

Figure 4. The loss-functions for the training and validation parts: a) BCE; b) MSE.

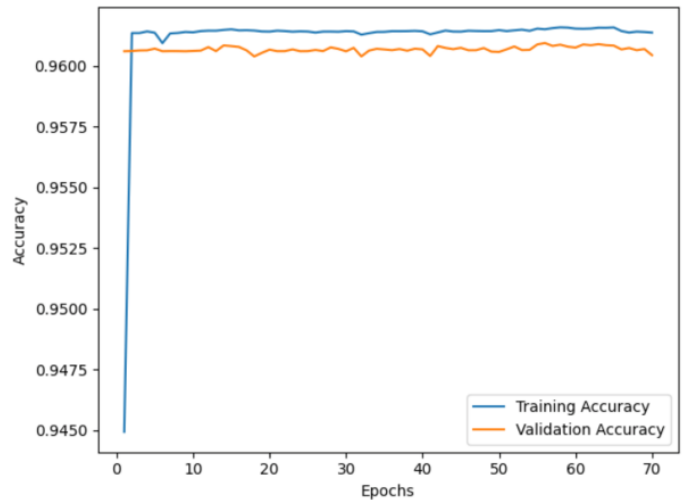

(a)

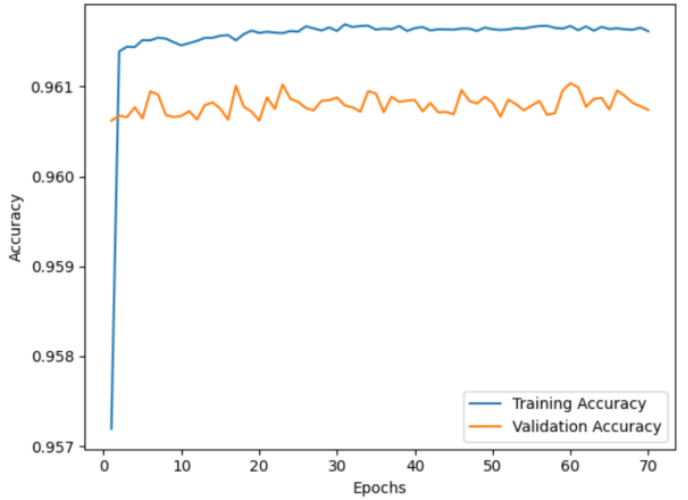

(b)

Figure 5. The accuracy for the training and validation parts: a) BCE; b) MSE.

MSE gives slightly better result. In figure 6 images for 2 loss functions are presented. 


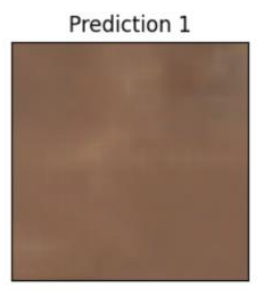

Prediction 2

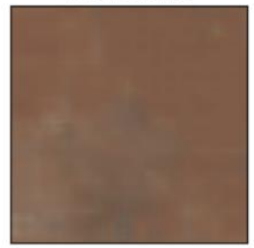

Exact value 1

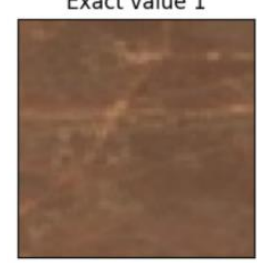

Exact value 2

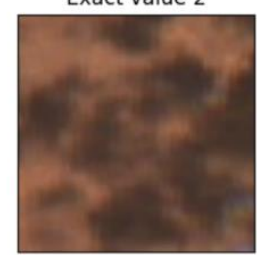

Prediction 1

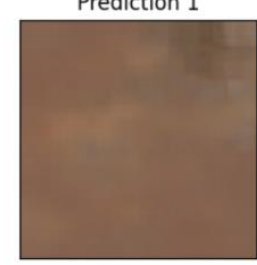

Prediction 2

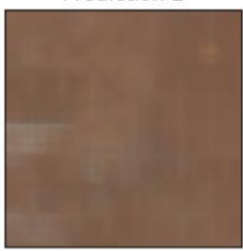

(b)

(a)

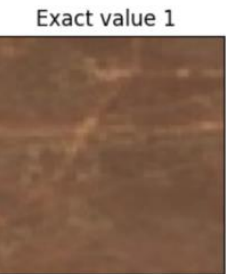

Exact value 2

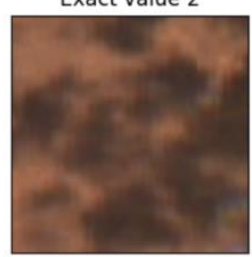

Figure 6. The outcomes of the network: a) BCE; b) MSE.

Accuracy is about $96 \%$. It is good enough for the second stage.

\section{Conclusion}

The described method allows not only to conduct a qualitative and quantitative analysis of land changes, but also to make a prediction. It is necessary to form dataset for the second stage and conduct experiments. The last step is to connect the outcomes of the networks to make conclusions about soil condition.

\section{References}

[1] Dedova E.B., Gol'dvarg B.A., Cagan-Mandzhiev N.L. Degradaciya zemel' Respubliki Kal mykiya: problemy i puti vosstanovleniya [Land degradation in the Republic of Kalmykia: problems and ways of restoration] // Aridnye ekosistemy, 2020. tom 26 - №2(83). - S. 63-71.

[2] Trofimov I.A., Trofimova L.S., Yakovleva E.P. Distancionnye indikatory opustyni vaniya zemel' [Remote indicators of land desertification]. // Aridnye ekosistemy, 2015. tom 21 - №1(62). - S. 5-22.

[3] Earth Engine Data Catalog. Available at: https://developers.google.com/earthengine/datasets/catalog/COPERNICUS_S2_SR (accessed 30.05.2021)

[4] Nikolenko S., Kadurin A Arhangel'skaya E. Glubokoe obuchenie [Deep learning] // Saint Petersburg, Piter Publ., 2019. 480 p.

[5] Bajkalova T.V. Monitoring i ocenka dinamiki razvitiya erozionnyh processov na zemlyah sel'skohozyajstvennogo naznacheniya [Monitoring and assessment of the dynamics of the development of erosion processes on agricultural lands]. // Vestnik Altajskogo gosudarstvennogo agrarnogo universiteta, 2018. - №6(164). - S. 61-67. 